\title{
Satellite Imagery Assists in the Assessment of Hail Damage for Salvage Harvest
}

\author{
by M.D. Gillis ${ }^{1}$, R.D. Pick ${ }^{2}$ and D.G. Leckie ${ }^{1}$
}

\begin{abstract}
On June 8, 1987 a severe thunderstorm caused extensive hail damage to portions of the forest within Algonquin Provincial Park, Ontario. The Algonquin Forestry Authority, charged with the responsibility for harvest operations within the Park, decided to salvage the damaged forest. A map of the damage was required to determine the area and volume to be harvested. A cooperative project between the Algonquin Forestry Authority and the Petawawa National Forestry Institute was established to map the damaged area by combining satellite imagery and existing ground information and to define the cut blocks using the satellite data as a guide for field work. A colour composite transparency of Landsat Thematic Mapper data was acquired and the damaged area mapped in just over two weeks. The satellite imagery in combination with ground work provided a simple, effective, and timely method for assessing hail storm damage for an operational salvage harvest.
\end{abstract}

\section{Résumé}

Le 8 juin 1987, un violent orage, accompagné de grêle, a causé des dommages importants dans des parties de la forêt du parc provincial Algonquin. L'Agence de foresterie du parc Algonquin, chargés des opérations de coupe dans le parc, a décidé de récupérer les arbres endommagés. Elle avait besoin d'une carte des dommages pour déterminer l'emplacement et le volume des coupes à effectuer. Il s'est donc associé à une équipe de l'Institut forestier national de Petawawa afin d'établir une telle carte à l'aide d'images satellite et des données de terrain existantes et de délimiter les blocs de coupe en utilisant les données satellite comme guide pour les travaux sur le terrain. Une image en composition colorée produite à partir des données du Thematic Mapper de Landsat a été obtenue, et les zones de dommages ont pu être cartographiées en juste deux semaines. Les images de Landsat, combinées aux données de terrain, ont offert un moyen simple, efficace et rapide d'évaluer les dommages causés par la grêle en vue d'une coupe de récupération.

\section{Introduction}

The application of satellite imagery to investigate forest management problems is more appropriate and widespread than is generally thought. Many of the successful applications are for small projects of local importance, which are usually not reported in the literature. This article reports on an operational application of satellite imagery to assess storm damage for the purpose of salvage harvest planning.

\section{Background}

Algonquin Park is a one-million-hectare provincial park reserve in eastern Ontario (Figure 1). The Park is located within the Great Lakes-St. Lawrence Forest Region (Rowe 1972). The forests are characterized by eastern white and red pines (Pinus strobus L. and $P$. resinosa Ait.), eastern hemlock (Tsuga canadensis (L.) Carr.) and various hardwoods such as red oak (Quercus rubra L.), sugar maple (Acer saccharum Marsh.), basswood (Tilia americana L.) and poplar species (Populus spp.). The topography of the area is strongly rolling upland terrain with shallow soils on the upland sites and deeper soils in the valleys. The Algonquin Forestry Authority is an Ontario crown corporation responsible for timber harvesting in the Park, and for product distribution to dependent mills.

On June 8, 1987 a thunderstorm swept through Algonquin Park causing severe hail damage to portions of the forest in

\footnotetext{
${ }^{1}$ Forestry Canada, Petawawa National Forestry Institute, Chalk River, Ontario.

${ }^{2}$ Algonquin Forest Authority, Pembroke, Ontario.
}

Master Township. Hail stones up to $2 \mathrm{~cm}$ in diameter caused branches to break off, needle loss, and lacerations to the main stem and branches in the crowns of most trees (Figure 2). Most of the damage was to the windward side of the crown. The damage was greater for the softwood species, especially the pine on the ridge tops. The loss of foliage and broken branches were first detected in August, 1987 by Ontario Ministry of Natural Resources pilots who were ferrying work crews between sites in the area. A subsequent ground check of the area led to the decision to monitor the situation. On a planned mission to map areas of prescribed burn adjacent to Algonquin Park, it was decided to also acquire supplemental aerial photography (SAP) to document the hail damage. Black and white SAP was acquired in February 1988 from an altitude of approximately $1500 \mathrm{~m}$ using a $35 \mathrm{~mm}$ camera with $24 \mathrm{~mm}$ lens. This yielded a working scale of 1:8000 on 25 by $17 \mathrm{~cm}$ enlarged prints. Because of the type of film used and the time of year of acquisition only a general indication of the area of damage could be interpreted from this imagery.

A spot check conducted in spring 1988 indicated a new crop of stunted needles. As a result of this observation it was thought that all species would recover and no significant loss of timber was expected. However, a routine aerial reconnaissance of the area in late August 1988, discovered signs of stress in the more severely damaged trees. Symptoms of the stress were browning needles followed by varying levels of defoliation (Figure 3). Higher levels of defoliation were prevalent in the white pine. Some red pine trees had died with all the foliage having turned red-brown. Hardwoods also exhibited signs of stress (i.e. early autumn colouring). 


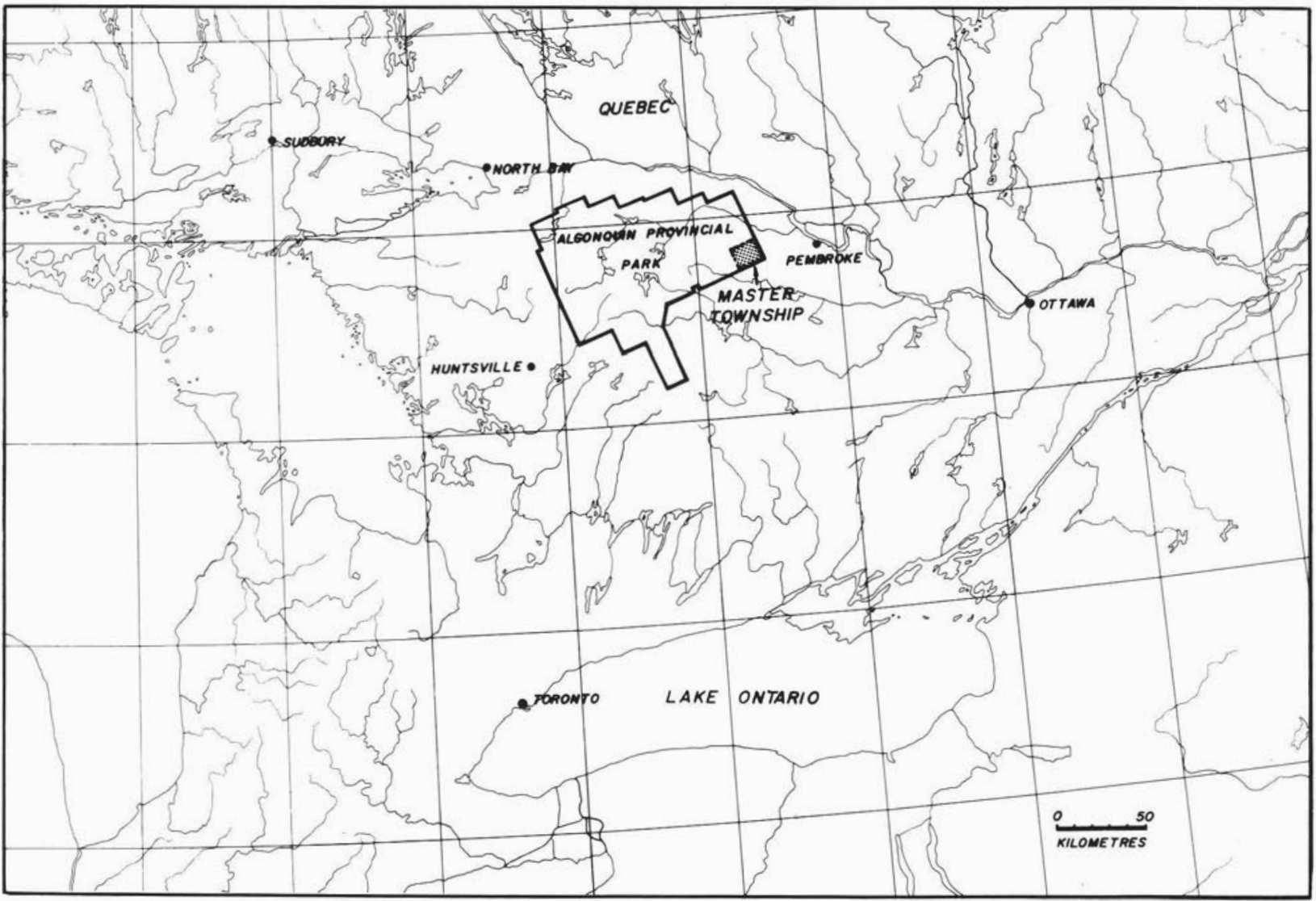

Figure 1. The location of Master Township within Algonquin Provincial Park.

These symptoms of stress to pine are often accompanied by insect infestation and wood staining. This results in a 'downgraded' or much less valuable product following harvest. Damaged trees indeed did show staining and insect damage. Because of the small chance of recovery of many of the trees and the potential loss in product value, the Algonquin Forestry Authority, in consultation with the Ontario Ministry of Natural Resources, decided to harvest the damaged pine. Because of the rapid deterioration of wood quality associated with this form of stress, a salvage operation had to be planned and implemented quickly. To plan an effective salvage harvest operation it was necessary to determine the area and volume to be harvested. An attempt was made to combine the winter SAP with spot ground checks. This procedure provided a rough estimate of the area and volume, but it did not provide the level of detail required to plan and conduct a salvage operation. A better definition of the area and severity of damage was required for establishing cut blocks. Several options were considered including, new SAP, aerial sketchmapping, and an intensive ground survey. Following consultation with the Petawawa National Forestry Institute (PNFI), a cooperative project was established to map the area of stress by combining information from satellite imagery and ground work.

Figure 2. Lacerations through the bark of a white pine branch caused by hailstones (September, 1988).

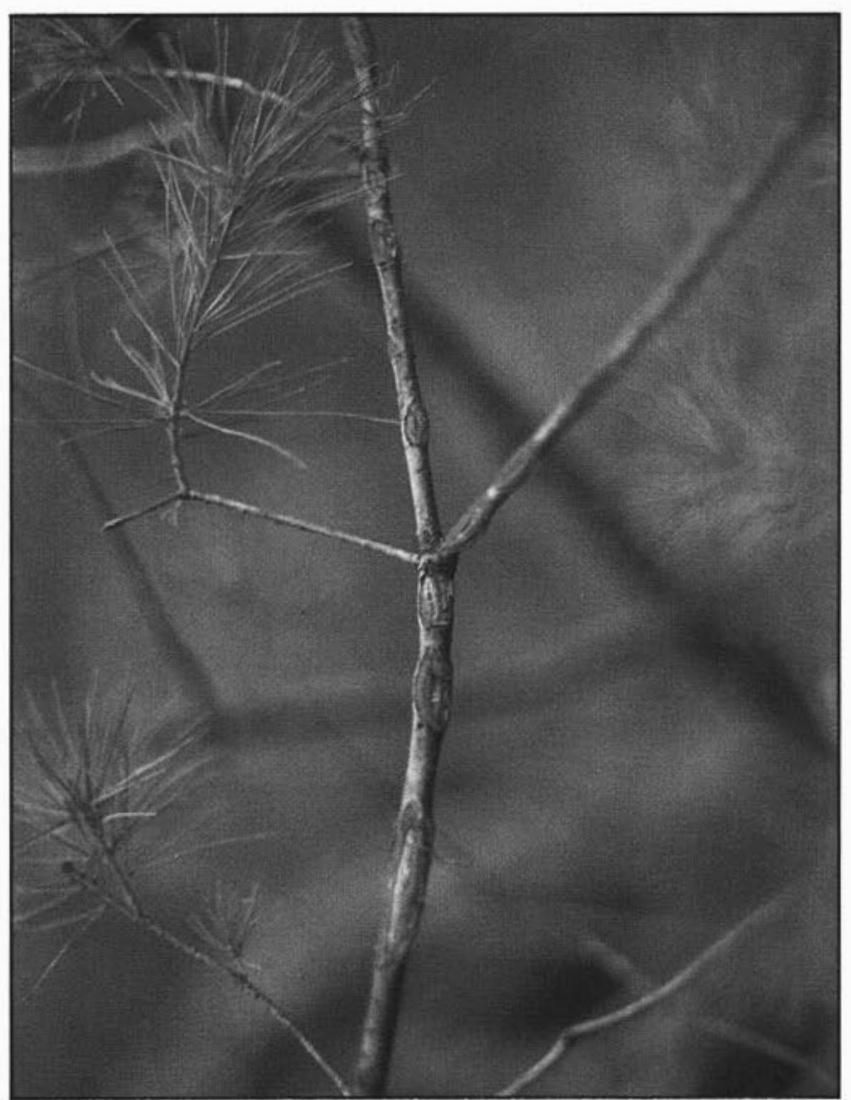




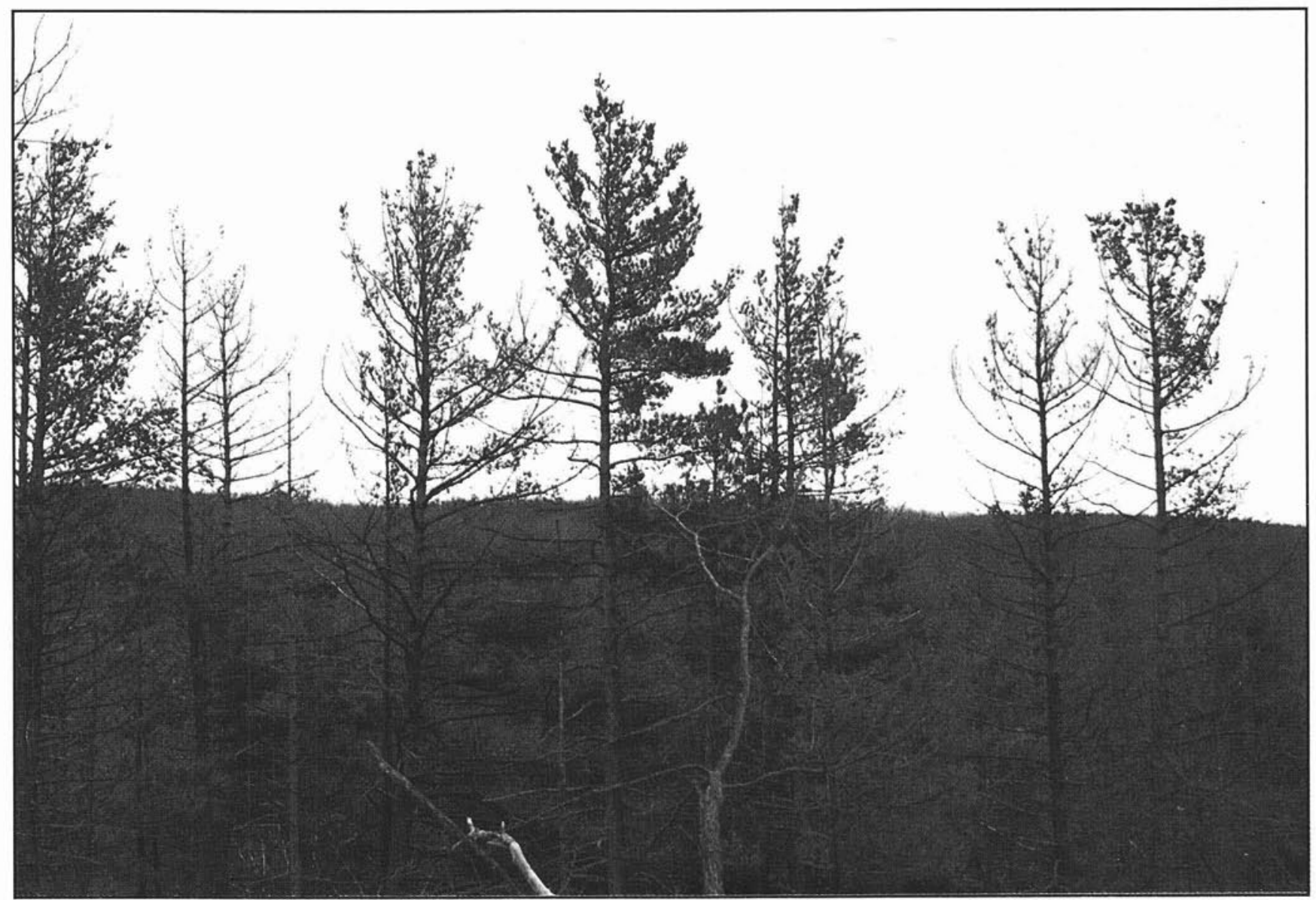

Figure 3. Hail damage to the crowns of white pine trees.

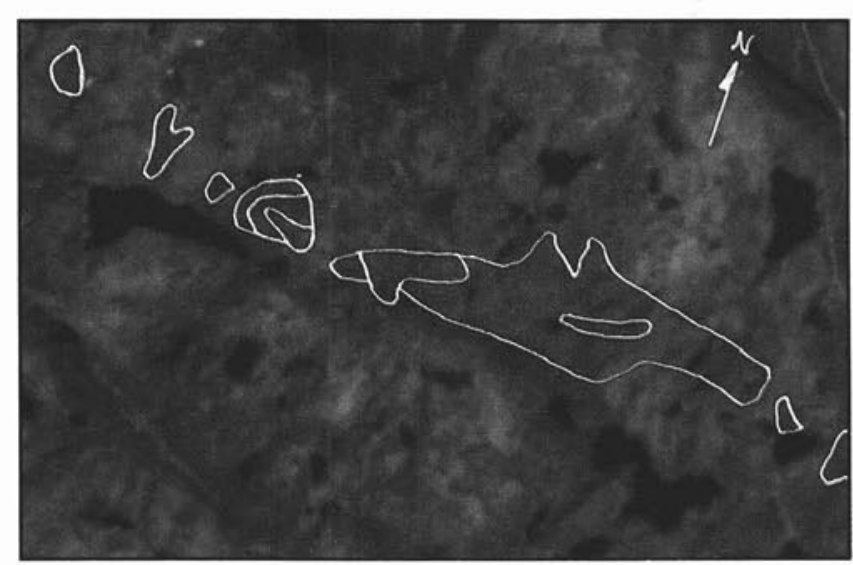

Figure 4. The damage area delineated onn Landsat 5 Thematic mapper imagery (scale approximately 1:200 000).

\section{Project Activities}

Landsat 5 Thematic Mapper (TM) data of the damage area was available for June 7, 1988. A colour composite transparency with the red band $3(0.63-0.69 \mu \mathrm{m})$, near-infrared band $4(0.76-0.90 \mu \mathrm{m})$ and middle infrared band 7 $(2.08-2.35 \mu \mathrm{m})$ represented by the colours blue, green and red respectively, was ordered from the Prince Albert Satellite Station. This combination of bands and colours was chosen for its ability to depict vegetation stress (Ahern 1987).
The transparency was ordered September 6, and received September 22. Analysis was carried out September 23. A Procom-2 optical transfer device (Moore 1986), at PNFI was used to scale and project the TM transparency $(1: 1000000)$ onto the 1:15 840 Ontario Forest Resources Inventory (FRI) map of the area.

A healthy forest produces a uniform green colour pattern with this band and colour combination. A rusty brown colour deviation from the expected green coincided with specific areas of known damage based on existing field observation (Figure 4). This anomalous colouration is consistent with what might be expected from the stress symptoms of browning needles and loss of foliage. The rusty brown colour likely results from a shift from the green hues of healthy vegetation to red and brown hues because of a decrease in near-infrared reflectance, and increases in middle infrared and red reflectances commonly associated with both the red colouration of foliage under stress and defoliation (Leckie et al. 1988a, Leckie et al. 1988b). Similar colouration of Landsat TM red, near-infrared and middle infrared band composites was noted by Ahern and Archibald (1986) for several other types of forest damage.

Personnel from the Algonquin Forestry Authority transferred the pattern to the FRI map (Figure 5), distinguishing between light and heavy damage from the intensity of the rusty brown colour on the transparency. The interpreted damage zones, shown in Figure 4, are 105 ha of heavy and 350 ha of light damage. This delineation provided a guide 


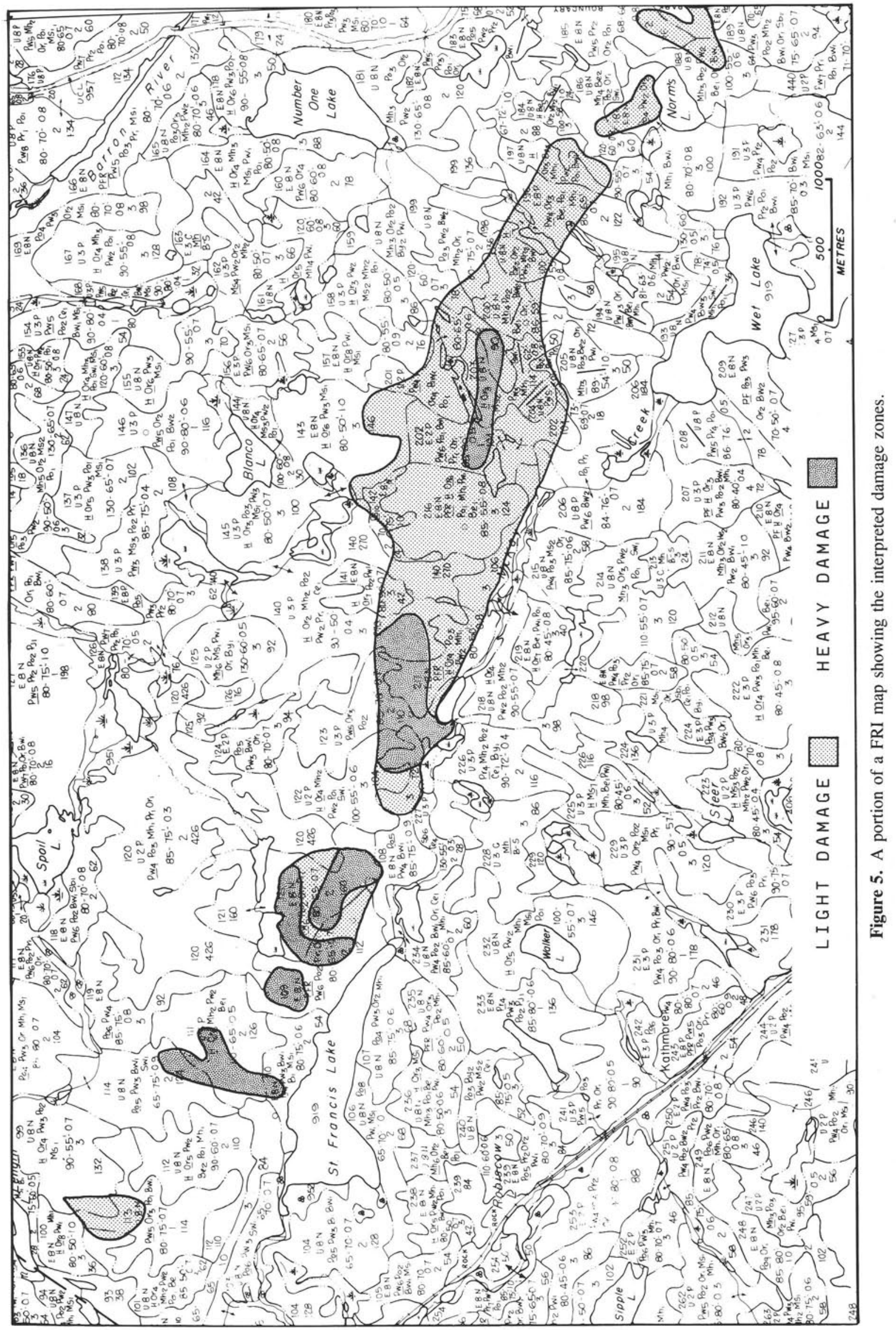




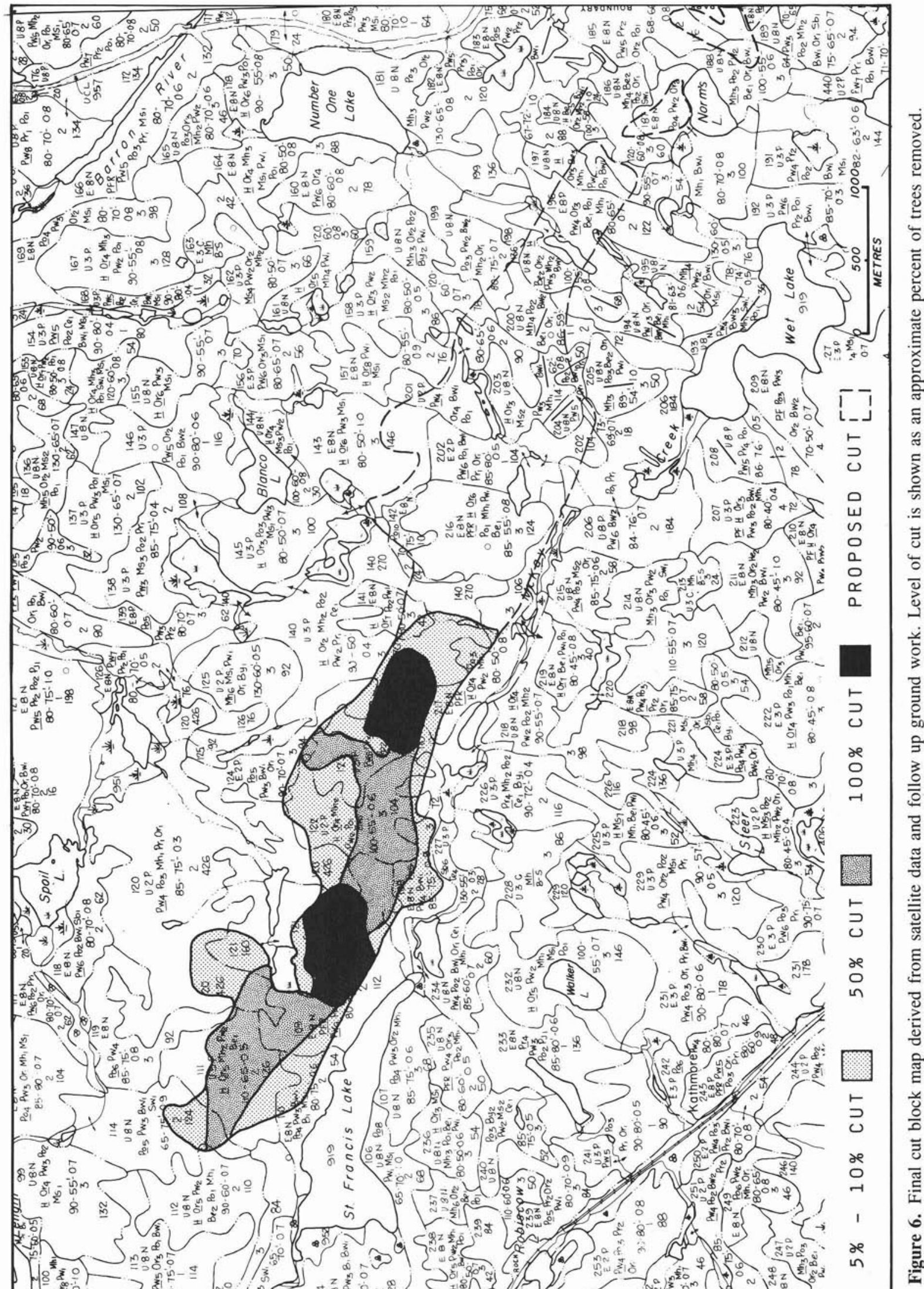


for cut block establishment. Based on satellite imagery field workers were able to efficiently locate and establish cut blocks in areas of heavy and light damage. Some areas of light damage were deleted from salvage plans because a shortage of wood volume made logging impractical. As well, some areas of low damage not detected by the satellite were added to the plan. The final cut block map is shown in Figure 6. Harvesting was planned to be undertaken in two stages due to physical barriers and access problems. The area marked for the first stage of salvage and tendered to contract was 360 hectares. The volume was estimated by multiplying the area of each stand to be cut by the appropriate yield table value and then aggregating the stand values. The initial volume estimate for the first stage of harvest, based on the SAP and ground spot checks, was $16000 \mathrm{~m}^{3}$. The final volume estimate for the planned logging operation, derived from satellite interpretation and ground work and used in final contracting, was $10000 \mathrm{~m}^{3}$. The difference led to a decision to hire one rather than two contractors. The actual volume harvested from 360 hectares was $10040 \mathrm{~m}^{3}$. The second stage of logging operations, scheduled for 1989 , is shown in Figure 6.

\section{Discussion}

Satellite imagery combined with ground work provided a simple, cost effective, and timely method for assessing hail storm damage for operational forest harvest planning. An effective damage map was produced from the satellite data and existing ground knowledge. Subsequent ground work confirmed the interpretation of the satellite imagery and the satellite damage map (Figure 5) matched well with the final cut block map (Figure 6), which is a good representation of conditions on the ground. The damage map provided an excellent guide for the establishment of cut blocks.

Algonquin Forestry Authority personnel were not familiar with the use of satellite imagery nor the projection system used for mapping yet quickly learned how to apply the technology and were soon discussing how satellite imagery may be applied to other forest management problems.

This method cost a total of $\$ 325$ for the imagery, and one half day for analysis and mapping (mapping is done as part of the interpretation). The follow up ground work to establish the cut blocks took nine days and cost $\$ 1500$. This cost and effort was comparable with or less than other methods. Other methods of producing an initial map of damage, such as ground reconnaissance, SAP, and sketch mapping, would require the equivalent amount of follow-up ground work. A ground reconnaissance, estimated to cost $\$ 1000$, would have provided a less accurate delineation of the damage area. The cost would be considerably more if the damage had been more widespread or scattered. New SAP was estimated to cost $\$ 300$, with a day required for interpretation and transfer to map. The cost of sketch mapping from helicopter was estimated to be between $\$ 500$ and $\$ 1000$. Helicopters would have to be employed to provide the level of detail required to map tree stress. The cost of field work necessary to calibrate the interpretation is not included in any estimate as the necessary knowledge had been obtained from previous field work. Intensive field work is not required for this calibration. Normal ground reconnaissance, typically undertaken with such damage occurrences, would be sufficient to calibrate the interpretation.

Finally, the method employed was very timely. The satellite data were ordered, acquired, interpreted, and a map was produced in just over two weeks. The timeliness, however, is dependent on the availability of appropriate existing satellite data, or the ability to acquire new cloud-free imagery in the required time frame.

\section{Summary}

For this forest management application, satellite information was available and was used to efficiently delineate an area of known stress for salvage harvesting. The application of satellite imagery to map forest stress was comparable in cost to other methods and provided timely map information required to determine volume and define cut blocks for salvage harvest planning.

\section{Acknowledgements}

The authors wish to thank T. Hiscock of the Ontario Ministry of Natural Resources - Pembroke, D. Janke of the Algonquin Forestry Authority, and G. Griffith of Forestry Canada - Petawawa National Forestry Institute for their assistance with this report.

\section{References}

Ahern, F.J. and P.D. Archibald. 1986. Thematic mapper information about Canadian forests: early results from across the country. Proc. 10th Canadian Symposium on Remote Sensing, Edmonton, Alta., May 5-8, 1986. pp. 683-697.

Ahern, F.J. 1987. TM band combinations. Can. Cen. for Remote Sens. Newbrief. 2 p.

Leckie, D.G., P.M. Teillet, D.P. Ostaff, and G. Fedosejevs. 1988a. Sensor band selection for detecting current defoliation caused by spruce budworm. Remote Sens. Environ. 26: 31-50.

Leckie, D.G., P.M. Teillet, G. Fedosejevs, and D.P. Ostaff. 1988b. Reflectance characteristics of cumulative defoliation of balsam fir. Can. J. For. Res. 18: 1008-1016.

Moore, W.C. 1986. Procom-2 mapping technique for monitoring forest depletion. For. Man. Notes No. 32. Nov. For. Cen., For. Can. 7 p.

Rowe, J.S. 1972. Forest Regions of Canada. Dep. Fisheries and Environ. Can. For. Serv., Publ.No. 1300. 